University of Wollongong

Research Online

Faculty of Engineering and Information

Faculty of Engineering and Information

Sciences - Papers: Part B

Sciences

2019

Changes in the incidence and uptake of reproductive surgery versus in vitro fertilisation in Australia between 2001 and 2015: A population-based study

Leon Foster

Stephen Robson

Anusch Yazdani

Pauline Y. O'Shaughnessy

University of Wollongong, poshaugh@uow.edu.au

Follow this and additional works at: https://ro.uow.edu.au/eispapers1

Part of the Engineering Commons, and the Science and Technology Studies Commons

Research Online is the open access institutional repository for the University of Wollongong. For further information contact the UOW Library: research-pubs@uow.edu.au 


\title{
Changes in the incidence and uptake of reproductive surgery versus in vitro fertilisation in Australia between 2001 and 2015: A population-based study
}

\author{
Abstract \\ (C) 2018 The Royal Australian and New Zealand College of Obstetricians and Gynaecologists Objective: \\ Improvements in success rates of assisted reproduction led to predictions that infertility surgery in both \\ women and men would become extinct in developed countries. We sought to identify the changes in \\ reproductive surgery that occurred between 2001 and 2015 to determine whether these predictions have \\ been accurate. Design: The Australian Institute of Health and Welfare (AlHW) national procedural dataset \\ and the Australian Medicare Benefits Scheme (MBS) claims database were searched for procedure data \\ for male and female reproductive surgery and assisted reproduction from January 2001 to December \\ 2015. The denominators were based on annual point estimates of the total population aged 25-44 years \\ (female) and 25-55 years (male) from the Australian Bureau of Statistics (ABS). This dataset provides \\ procedures undertaken but not their indications. Results: Over the study period the incidence of tubal \\ surgery fell by $66 \%$, vasectomy reversal by $33 \%$, and surgical varicocoelectomy by $50 \%$. In contrast, the \\ rate of hysteroscopic myomectomy increased by $48 \%$, hysteroscopic septoplasty by $125 \%$, and \\ laparoscopy for severe endometriosis increased by $84 \%$. In vitro fertilisation oocyte retrievals increased \\ by $90 \%$. The rate of abdominal myomectomy was unchanged. Conclusion: Fertility surgery is not dead but \\ has evolved. \\ Disciplines \\ Engineering | Science and Technology Studies

\section{Publication Details} \\ Foster, L., Robson, S., Yazdani, A. \& O'Shaughnessy, P. (2019). Changes in the incidence and uptake of \\ reproductive surgery versus in vitro fertilisation in Australia between 2001 and 2015: A population-based \\ study. Australian and New Zealand Journal of Obstetrics and Gynaecology, 59 (2), 272-278.
}




\title{
Changes in the incidence and uptake of reproductive surgery versus in vitro fertilisation in Australia between 2001 and 2015: A population-based study
}

\author{
Leon Foster ${ }^{1}$ (D) , Stephen J. Robson ${ }^{2}$ (D) , Anusch Yazdani ${ }^{3}$ (D) and \\ Pauline Y. O'Shaughnessy ${ }^{4}$ (iD
}

${ }^{1}$ Centenary Hospital for Women and Children, Canberra, Australian Capital Territory, Australia

${ }^{2}$ Australian National University, Canberra, Australian Capital Territory, Australia

${ }^{3}$ The University of Queensland, Brisbane, Queensland, Australia

${ }^{4}$ School of Mathematics and Applied Statistics, The University of Wollongong, Wollongong, New South Wales, Australia

Correspondence: Registrar Leon Foster, Centenary Hospital for Women and Children, 77 Yamba Drv, Garran, ACT 2605 Australia. Email: leon.foster@act.gov.au

Conflict of Interest: L. Foster, S. Robson and P. O'Shaughnessy declare no financial or non-financial competing interests. A. Yazdani is a minor shareholder in Virtus Health.

Capsule: Was the prediction that IVF would lead to the death of fertility surgery accurate?

The Australian experience from 2001 to 2015 .

Received: 5 June 2018; Accepted: 18 October 2018
Objective: Improvements in success rates of assisted reproduction led to predictions that infertility surgery in both women and men would become extinct in developed countries. We sought to identify the changes in reproductive surgery that occurred between 2001 and 2015 to determine whether these predictions have been accurate.

Design: The Australian Institute of Health and Welfare (AlHW) national procedural dataset and the Australian Medicare Benefits Scheme (MBS) claims database were searched for procedure data for male and female reproductive surgery and assisted reproduction from January 2001 to December 2015. The denominators were based on annual point estimates of the total population aged 25-44 years (female) and 25-55 years (male) from the Australian Bureau of Statistics (ABS). This dataset provides procedures undertaken but not their indications.

Results: Over the study period the incidence of tubal surgery fell by $66 \%$, vasectomy reversal by $33 \%$, and surgical varicocoelectomy by $50 \%$. In contrast, the rate of hysteroscopic myomectomy increased by $48 \%$, hysteroscopic septoplasty by $125 \%$, and laparoscopy for severe endometriosis increased by $84 \%$. In vitro fertilisation oocyte retrievals increased by $90 \%$. The rate of abdominal myomectomy was unchanged.

Conclusion: Fertility surgery is not dead but has evolved.

\section{KEYWORDS}

assisted reproductive treatment, fertility surgery, IVF, tubal surgery

\section{BACKGROUND}

In 2008, Feinberg, Levens and de Cherney predicted that 'infertility surgery is dead: only the obituary remains. ${ }^{1}$ The authors made their prediction on the basis of three premises: that the results of assisted reproductive treatment (ART) continued to improve; that the time from treatment to pregnancy is much quicker with ART; and that ART carries less risk than that associated with prolonged surgery and anaesthesia. Over the last decade, advances in the methods and scope of ART procedures and treatments have been associated with increased uptake. In 2015, 4.3\% (13 344) of the 308887 babies born in Australia, were conceived via ART. ${ }^{1,2}$

The role of surgery in female factor infertility lies in the establishment of an aetiology, the treatment of abnormalities, and, potentially, the optimisation for ART. These aims are 
addressed by hysteroscopic procedures (such as polypectomy, myomectomy, septoplasty and division of adhesions), laparoscopic procedures (including salpingostomy for hydrosalpinx, fimbrioplasty, tubal anastomosis, myomectomy, and laparoscopic treatment of endometriosis and endometrioma), and open surgery (including myomectomy and tubal surgery). In men, the canon of reproductive surgery (excluding invasive procedures to obtain sperm for ART) encompasses vasectomy reversal and varicocelectomy. We used Australian data to identify changes and trends in the incidence and uptake of reproductive surgery between 2000 and 2015 to confirm or refute Feinberg and colleagues' prediction.

\section{MATERIALS AND METHODS}

Data were extracted from two mandated Australian national data collections, the Australian Institute of Health and Welfare (AlHW) national procedural dataset and the Australian Medicare Benefits Scheme (MBS) claims database, from January 2001 to December 2015. For procedural data regarding inpatient fallopian tube surgery, laparoscopic and open myomectomy, anastomosis of the vas deferens and epididymis, and varicocelectomy, the source was the AlHW national procedural dataset. ${ }^{3}$ These data are collected under the auspice of the Australian Health Ministers' Advisory Council (AHMAC) through the National Health Information Agreement. The data are collected as specified in the National Minimum Data Sets relating to hospitals and day procedure facilities and are compiled by pooling data supplied by all Australian state and territory health authorities. All procedures performed in Australian facilities are coded according to the agreed national standard, the Australian Classification of Health Interventions (ACHI), ${ }^{4}$ which is based around the Australian National MBS. We selected procedures coded according to the International Classification of Diseases-10-AM/ACHI guidelines, as detailed in Box 1. Validation studies of the AlHW dataset have reported $99.5 \%$ agreement with 'true' morbidity (kappa 0.86). ${ }^{5}$

To quantify the uptake of in vitro fertilisation (IVF) procedures and rate of laparoscopic resection of endometriosis, we used the Australian MBS claims database. Surgery for less severe endometriosis (levels I-III) was not included as the database was unable to provide sufficiently accurate data for these procedures. Medicare data include services performed by a registered provider for services that qualify for a benefit, and for which a claim has been processed. As this is the basis of remuneration for all procedures, this database is subject to audit by the Australian National Audit Office and the Professional Services Review (PSR) scheme. The dataset has been audited and found to be extremely accurate. ${ }^{6}$ The PSR audit and recoup costs from fraudulent claims. ${ }^{7}$ This database does not include services provided by hospital doctors to public patients in public hospitals, or services that qualify for a benefit under the Department of Veterans' Affairs (DVA) National Treatment Account.

\section{BOX 1}

\section{Male procedures}

ICD procedure codes

30635-00 Repair of varicocoele

37616-00 Microsurgical vasovasostomy, unilateral

37616-01 Mircrosurgical vasovasostomy, bilateral

37616-02 Microsurgical vaso-epididymostomy, unilateral

37616-03 Microsurgical vaso-epididymostomy, bilateral

37619-00 Vasovasostomy, unilateral

37619-01 Vasovasostomy, bilateral

37619-03 Vasoepididymostomy, bilateral

\section{Female procedures}

35694-00 Laparoscopic salpingoplasty

35694-01 Laparoscopic anastomosis of fallopian tube

35694-04 Salpingoplasty

35694-05 Anastomosis of fallopian tube

35697-00 Microsurgical salpingoplasty

35623-00 Uterine myomectomy via hysteroscopy

35634-00 Division of uterine septum via hysteroscopy

\section{MBS item number}

35641 Endometriosis level four or five, laparoscopic resection of, involving any two of the following procedures: resection of the pelvic side wall including dissection of endometriosis or scar tissue from the ureter, resection of the pouch of Douglas, resection of an ovarian endometrioma greater than $2 \mathrm{~cm}$ in diameter, dissection of bowel from uterus from the level of the endocervical junction or above: where the operating time exceeds $90 \mathrm{~min}$.

The 'reproductive age group, denominator' we used was 25-44 years inclusive for women and 25-55 years for men. Annual point estimates for the total Australian female population aged 25-44 years and men 24-55 years inclusive, were obtained from the Australian Bureau of Statistics (ABS). ${ }^{8}$

Data were analysed in Excel ${ }^{\mathrm{TM}}$ (Microsoft, 2017 Redmond, WA, USA). Datasets were subject to parametric and nonparametric analysis as applicable. Simple linear regression was performed in Excel using the least squares method. Trends generally say little about changes of uptakes of the procedures related to each other. To have a more comprehensive view of the change of the various reproductiveassisted procedures, we considered IVF oocyte retrieval as a reference and performed regressions on the ratios of given procedures relative to IVF oocyte retrieval. Investigation on the ratios reveals the relative changes of the fertility surgery to the rise of the assisted reproductive treatment, ie, do the fertility surgeries change proportional to the increasing popularity of the IVF? The study received prospective approval from the Human Research Ethics Committee of the Australian National University (protocol 2015/347). 


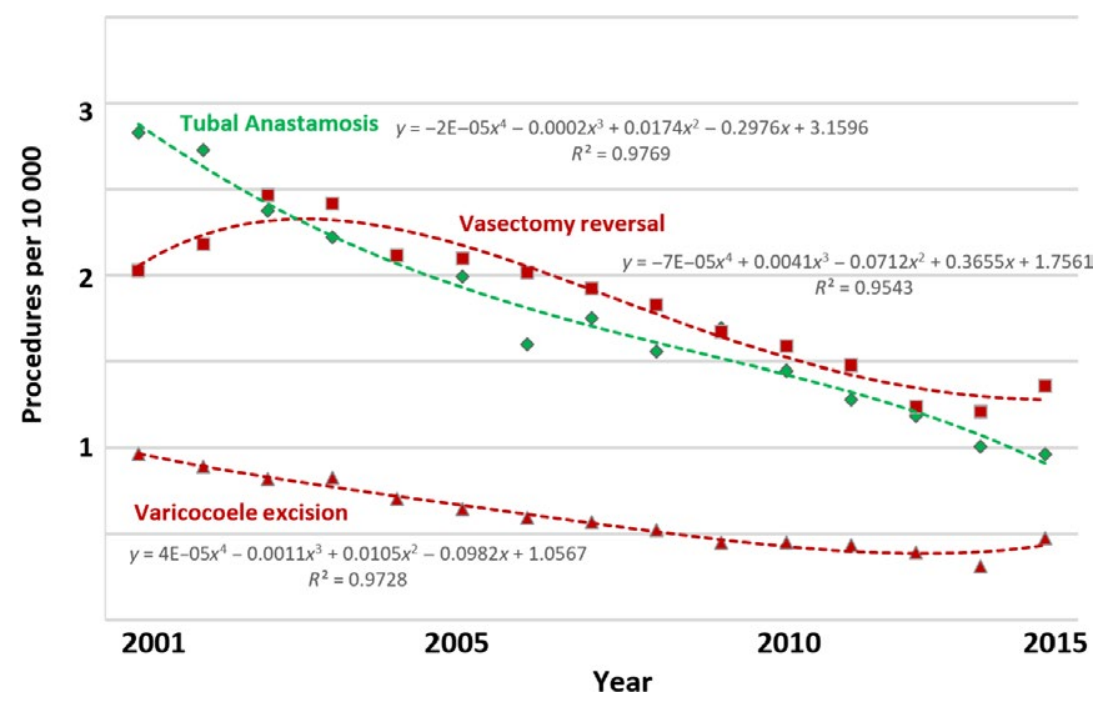

FI G URE 1 Age-stratified incidence rates (procedures per 10000 ) of fallopian tubal anastomosis ( $\diamond$ ) in women aged $25-44$ years and vasectomy reversal ( $\square$ ) and varicocoele excision ( $\mathbf{\Delta}$ ) in men aged 25-54 years for the period 2001-2015.

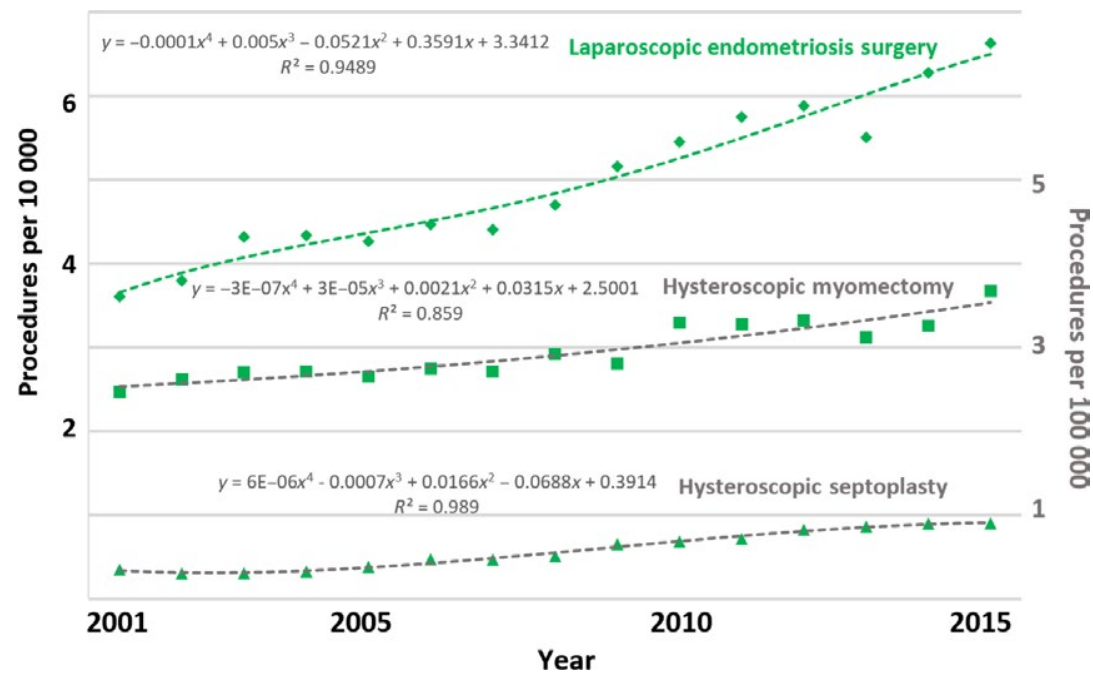

FIG URE 2 Age-stratified incidence rates (procedures per 10000 women aged 25-44 years) of laparoscopic surgery for levels four and five endometriosis $(\diamond)$, and for hysteroscopic myomectomy $(\square)$ and septoplasty $(\Delta)$ (procedures per 100000 women) for the period $2001-2015$.

\section{RESULTS}

Over the study period the incidence of tubal reconstructive surgery, vasectomy reversal, and varicocoelectomy declined significantly (Fig. 1). In contrast, the rates of hysteroscopic myomectomy, septoplasty, laparoscopic endometriosis surgery (Fig. 2) and IVF oocyte retrieval (Fig. 3) increased. While the overall rate of myomectomy has remained stable, the rate of open myomectomy decreased and laparoscopic myomectomy increased (Fig. 4).

The incidence of tubal surgery fell by $66 \%$ (from 2.83 to $0.96 / 10000 /$ year), vasectomy reversal by $33 \%$ (from 2.03 to $1.36 / 10000 /$ year), for surgical varicocoelectomy by $50 \%$ (from 0.96 to $0.48 / 10000 /$ year). In contrast, the rate of hysteroscopic myomectomy increased by $48 \%$ (from 0.25 to $0.37 / 10000 /$ year) hysteroscopic septoplasty by $125 \%$ (from 0.04 to $0.09 / 10000$ / year). Similarly, the rate of laparoscopy for severe endometriosis increased by $84 \%$ (from 3.61 to $6.63 / 10$ 000/year). IVF oocyte retrievals increased over the study by $90 \%$ (from 5.37 to $10.21 / 10000 /$ year); however, the significant change occurred only between 2000 and 2008, with no significant change from 2009 to 2015. The overall rate of open and laparoscopic myomectomy was $2.5 / 10000 / y e a r$. This remained stable throughout the period with the contribution of both procedures changing over time.

We found that tubal reconstruction, vasectomy reversal and surgical varicocoelectomy were negatively correlated with IVF, (Figs 1 and 3), consistent with the large positive coefficient in Table 1. Laparoscopic endometriosis surgery gained popularity over this time frame, similar to IVF oocyte retrievals, with non-significant difference in the trend $(P=0.069)$. 


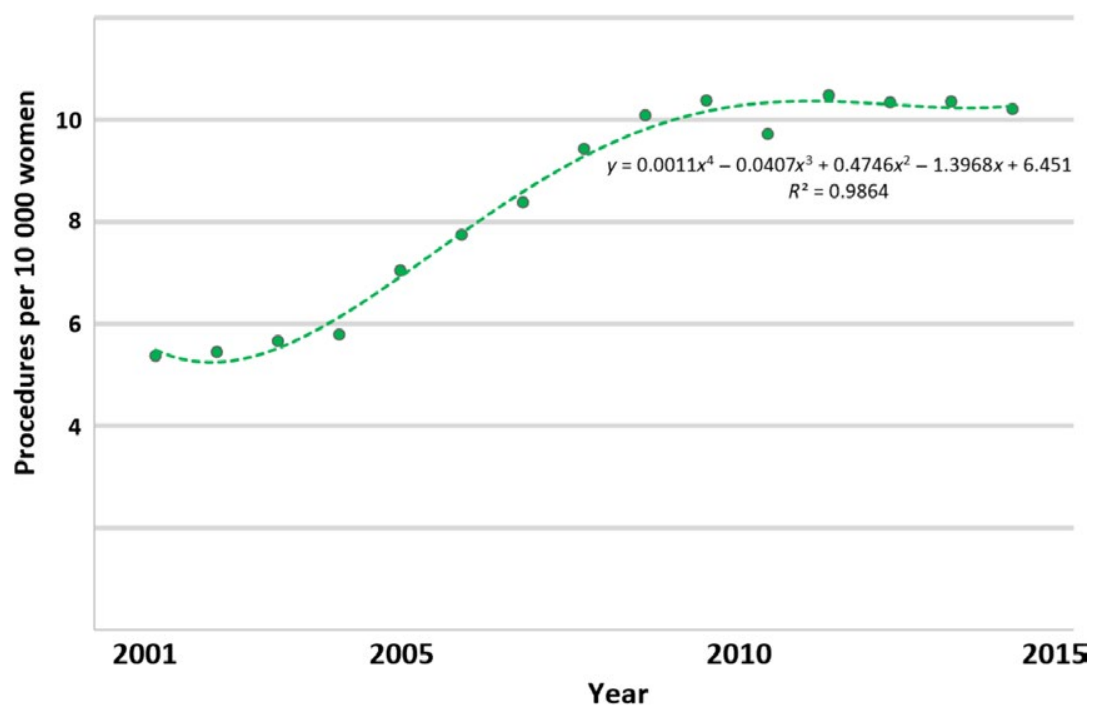

FIG URE 3 Age-stratified incidence rate of in vitro fertilisation (IVF) oocyte retrieval procedures in women aged 25-44 years in Australia (procedures per 10000 women), 2001-2015. Age-stratified incidence rates (procedures per 10000 women aged 25-44 years) of laparoscopic surgery for levels four and five endometriosis, for hysteroscopic myomectomy, and septoplasty.

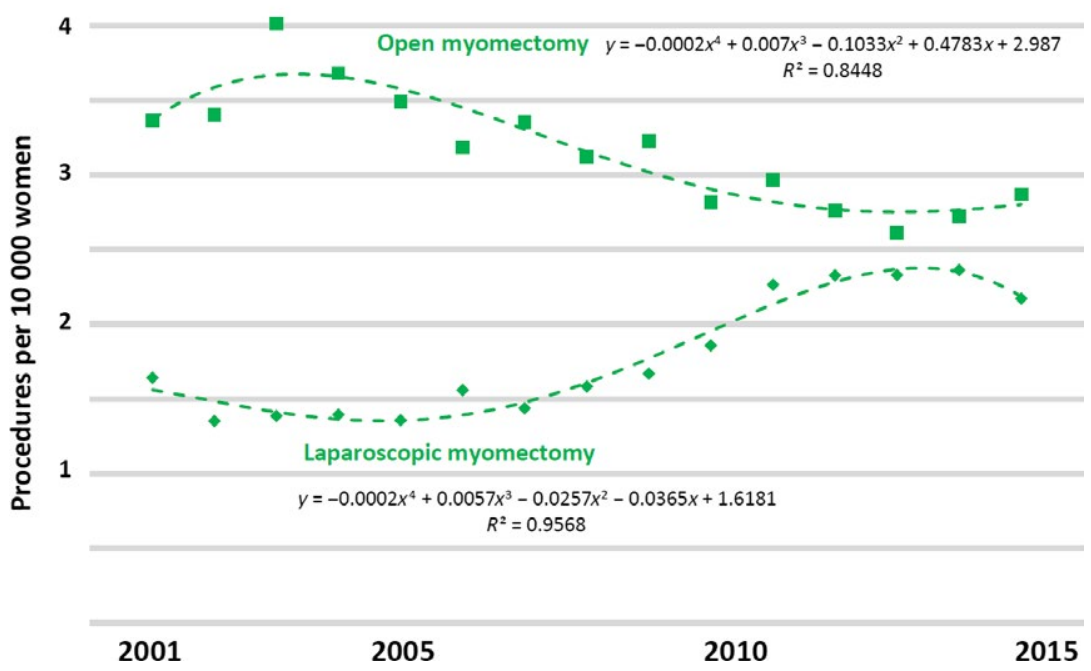

FIG URE 4 Age-stratified incidence rate of open $(\square)$ and laparoscopic $(\diamond)$ myomectomy in women aged 25-44, 2001-2015

\section{DISCUSSION}

This study has shown that, at a national level, some reproductive surgery procedures in women and men - notably tubal and vas surgery - have become much less common as Feinberg and colleagues predicted ten years ago. However, procedures such as the treatment of endometriosis and hysteroscopic procedures, have become more common.

The landscape of fertility surgery has shifted significantly in the new millennium. Before the era of ART, tubal surgery was the only option for fertility in a couple with tubal factor infertility and vasectomy reversal for men wishing additional pregnancies. However, between 2001 and 2015 the number of oocyte retrievals increased to $90 \%$. This was associated with an increase in the live delivery rate obtained with ART. In 2015 in Australia, 18\% of all cycles started ended in a live delivery up from just over $16 \%$ in $2002 .^{9}$

\section{Tubal reconstruction surgery}

The rate of spontaneous conception after tubal reconstructive surgery and vasectomy reversal can be high. For tubal reconstructive surgery, rates of spontaneous conception range from $69 \%$ in women with mild disease to $9 \%$ in women with severe tubal disease. ${ }^{10}$ For vasectomy reversal, the likelihood of sperm in the ejaculate and pregnancy rate depends on the time since vasectomy. Success rates are higher than $70 \%$ for sperm in the ejaculate and $30 \%$ for conception in a year, even 15 years after 
TABLE 1 Result of coefficients and $P$-values for ratio of surgical procedure to in vitro fertilisation oocyte retrieval

\begin{tabular}{|c|c|c|c|c|}
\hline & Response & Coefficient & SE & $P$-value \\
\hline Female & Ratio for laparoscopic endometriosis & 0.024 & 0.012 & 0.069 \\
\hline Male & Ratio for surgical varicocoelectomy & 1.431 & 0.141 & $<0.001$ * \\
\hline
\end{tabular}

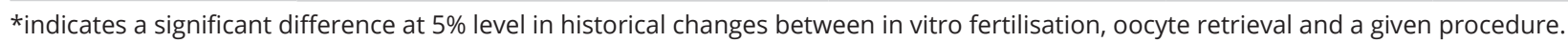

the initial vasectomy. ${ }^{11}$ The prevalence of vasectomy among married and coupled adults was stable during the period in question (13.7\% in 2001 and $14.0 \%$ in 2015). ${ }^{12}$

\section{Varicocele-ectomy}

Varicocele-ectomy to improve male subfertility is controversial. A 2012 Cochrane review found that the evidence that varicocoele decreases male fertility is poor and that no studies on treatment reported live birth as an outcome. Surgical correction, therefore, is similarly contentious and sperm optimisation, intracytoplasmic sperm injection (ICSI) and surgical sperm retrieval have decreased the need for varicocelectomy. ${ }^{13}$

\section{Changing pattern of Infertility}

During the same period the improvement in fertility outcomes, both spontaneous and ART, due to treatment of endometriosis and submucosal fibroids, polyps or septa has been reaffirmed. ${ }^{14,15}$

An aging maternal population has increasingly complex fertility issues, and surgery to improve fertility needs to adapt to this changing environment. Increasing maternal age effects fecundity as well as sees an increase in coexistent maternal disease, including tubal factor infertility, endometriosis and leiomyoma. ${ }^{15}$ The mean age of mothers in Australia has increased over the time period from 29.0 in 1999 to 30.3 in 2015. ${ }^{16,17}$ The mean age for women undertaking IVF was 35.5 in $2005^{9}$ and 35.9 in $2015^{2}$

In a population with decreasing fecundity, the option of immediate ART rather than tubal reconstruction unassisted pregnancy may be more expedient.

Over the study period the reported incidence of Chlamydia trachomatis infection in Australia increased more than threefold, with notifications increasing from 125 to 435 per 100000 between 2001 and $2011 .{ }^{18}$ Estimates of the attributable fraction of tubal factor infertility due to chlamydia vary widely: with estimates ranging between 11 and $15 \%$ to as high as $45 \% .{ }^{19,20}$

The increased uptake of bilateral salpingectomy for sterilisation, with its concomitant reduction in risk of ovarian cancer, creates a cohort of women for whom tubal reconstruction surgery is not possible. There has also been an overall decrease in the rate of tubal sterilisation procedures. In 2001 15.9\% of women utilised tubal sterilisation procedures which decreased to, on average, 5.3\% between 2005 and $2015 .^{12}$ The uptake of intrauterine device (IUD) usage also influences the requirement for and rate of reconstructive surgery. The rate of IUD use in Australia during this period was $1.3 \%$ of all contraceptive users, ${ }^{21}$ suggesting this has not had a dramatic impact on the rate of tubal reversal procedures. The level of these effects was unable to be determined in this study. ${ }^{22}$

\section{Leiomyoma}

Leiomyoma increases in prevalence and size as women age; the incidence in women aged 40 to 44 years is five times that of women aged 25-29 years. ${ }^{23}$ The presence of submucosal fibroids and polyps ${ }^{24}$ is associated with decreased fertility and their excision improves both spontaneous and ART fertility outcomes. ${ }^{25}$ The same is true of congenital uterine septum, the excision of which reduces the risk of spontaneous pregnancy loss and improves both spontaneous and ART pregnancy outcomes by up to fourfold. ${ }^{26,27}$ The overall effect of myomectomy for subfertility is unknown. The heterogeneity of the disease has led to multiple trials finding no benefit in laparoscopic myomectomy. There is likely to be a subset of women with intramural fibroids who would benefit from myomectomy to improve spontaneous fertility. ${ }^{23}$ Our finding of a fixed rate of myomectomy (open and laparoscopic) over the period supports the lack of a clearly identifiable group of women who benefit from the procedure. The increasing rate of hysteroscopic myomectomy (48\%) and hysteroscopic septoplasty (125\%) between 2000 and 2015 supports a shift in fertility surgery as well as more robust evidence regarding its efficacy.

We also found a significant increase in the rate of laparoscopy for 'severe' endometriosis. Endometriosis is thought to affect fertility by several mechanisms although there is no clear correlation between the clinical stage of endometriosis, symptoms and infertility. These effects include distorted pelvic anatomy due to adhesions, elevated inflammatory cytokines in the pelvis that might have adverse effects on oogenesis, ${ }^{28,29}$ fertilisation and tubal function, and impaired implantation. ${ }^{30}$ The optimal surgical and medical management of endometriosis for fertility remains debatable. The increase in surgery for stages III and IV endometriosis is line with the current recommendations from the American Society for Reproductive Medicine. ${ }^{31}$ 


\section{Endometriosis}

The increased effectiveness and accessibility of ART, especially ICSI and surgical or transcutaneous sperm retrieval, have meant that large numbers of quality sperm are no longer required for fertility. As these procedures can be performed in the fertility clinic with little to no surgical recovery or significant complications, they are, as our data indicate, replacing conventional vasectomy reversal and varicocelectomy. The male partner also does not require ongoing contraception post-conception.

The strengths of this study relate to the long period utilising accurate national statistics. However, the dataset does not allow identification of multiple procedures on an individual. The dataset also does not describe the indications for surgery and some procedures, for example myomectomy and endometriosis surgery, are performed for non-fertility indications. We were also unable to test confounders. Similarly, the small percentage of IVF procedures undertaken in public hospitals was not able to be determined. As only three of the 85 fertility clinics Australia-wide that contribute to the compulsory data set are named as public hospitals (3.5\%), the overall contribution of public hospital-based IVF procedures is likely to be very small. $^{2}$

Our data support the evolution, rather than the death, of fertility surgery. Higher success rates and faster conception times with ART are likely contributing factors in the reduction in the rate of surgery for both male and female tubal factor infertility. This shift in practice may lead to the extinction of these procedures as urologists and gynaecologists will not have sufficient surgical volume for training and skill maintenance. Conversely as the cohort of patients seeking fertility ages the number of procedures undertaken to assist them in spontaneous or assisted conception will continue to increase.

\section{REFERENCES}

1. Feinberg EC, Levens ED, DeCherney AH. Infertility surgery is dead: only the obituary remains? Fertil Steril 2008; 89: 232-236.

2. Fitzgerald O, Harris K, Paul RC, Chambers GM. Assisted Reproductive Technology in Australia and New Zealand 2015. Sydney: National Perinatal Epidemiology and Statistics Unit, the University of New South Wales Sydney, 2017.

3. Australian Institute of Health and Welfare (AlHW) National Procedural Dataset. Version 4.0. Last updated 4 August 2017. Australian Government Available via: https://www.aihw.gov.au/reports/ hospitals/procedures-data-cubes/contents/data-cubes Accessed: January 2018

4. AustralianInstituteofHealthandWelfare(AlHW).AustralianClassification of Health Interventions (ACHI) 10th Edit. Endorsed 10]uly 2017. [Accessed: January 2018.] Australian Government Available from: http:/ /meteor.aihw.gov.au/content/index.phtml/itemld/514008

5. Roberts $\mathrm{CL}$, Cameron CA, Bell JC et al. Measuring maternal morbidity in routinely collected health data: development and validation of a maternal morbidity outcome indicator. Med Care 2008; 46: 786-794.

6. Australian National Audit Officer. Accuracy of Medicare Claims Processing - Medicare Australia. The Auditor-General Audit report No.
20 2007-08 Performance report. Commonwelth of Australia, 2008. Available from: http://www.ag.gov.au/cca

7. Professional Services Review. Annual Report 2016 - 2017. Commonwealth of Australia, 2017. Available from: ww w.psr.gov.au/publications-and-resources/annual-reports

8. Australian Bureau of Statistics (ABS). Population. Australian Government. Last updated 24 April 2018. [Accessed: November 2017.] Available from: http://www.abs.gov.au/Population

9. Wang YA, Dean JH, Sullivan EA. Assisted Reproduction Technology in Australia and New Zaland 2005. In: Assisted reproduction technology series no 11 Cat No PER 36. Sydney: AlHW National Perinatal Statistics Unit, 2007.

10. Chua SJ, Akande VA, Mol BW. Surgery for tubal infertility. Cochrane Database Syst Rev 2017; 1: CD006415.

11. Belker AM, Thomas AJ Jr, Fuchs EF et al. Results of 1,469 microsurgical vasectomy reversals by the Vasovasostomy Study Group. J Urol 1991; 145: 505-511.

12. United Nations, Department of Economic and Social Affairs, Population Division. World Contraceptive Use 2018 (POP/DB/CP/Rev2018), 2018.

13. Kroese AC, de Lange NM, Collins J, Evers JL. Surgery or embolization for varicoceles in subfertile men. Cochrane Database Syst Rev 2012; 10: CD000479.

14. Tomazevic $\mathrm{T}$, Ban-Frangez $\mathrm{H}$, Virant-Klun I et al. Septate, subseptate and arcuate uterus decrease pregnancy and live birth rates in IVF/ICSI. Reprod Biomed Online 2010; 21: 700-705.

15. Nesbitt-Hawes EM, Campbell N, Maley PE et al. The surgical treatment of severe endometriosis positively affects the chance of natural or assisted pregnancy postoperatively. Biomed Res Int 2015; 2015: 438790

16. Laws PJ, Li Z, Sullivan EA. Australia's mothers and babies 2008. In: Perinatal statistics series no 24 Cat no PER 50. Canberra: AlHW, 2010.

17. Australian Institue of Health and Welfare. Australia's Mothers and Babies 2015 - in Brief. Canberra: AlHW, 2017.

18. Australian Bureau of Statistics. National Notifiable Diseases Surveillance System. In: Statistics AD, ed. Vol. cat. No 3101.0, Canberra: Australian Bureau of Statistics, 2011.

19. Gorwitz RJ, Wiesenfeld HC, Chen PL et al. Population-attributable fraction of tubal factor infertility associated with chlamydia. Am J Obstet Gynecol 2017; 217: e1-e16.

20. Price MJ, Ades $A E$, Welton NJ et al. How much tubal factor infertility is caused by Chlamydia? Estimates based on serological evidence corrected for sensitivity and specificity. Sex Transm Dis 2012; 39: 608-613.

21. Buhling KJ, Zite NB, Lotke $P$, Black K, INTRA Writing Group. Worldwide use of intrauterine contraception: a review. Contraception 2014; 89: 162-173.

22. Ely LK, Truong M. "The role of opportunistic bilateral salpingectomy vs tubal occlusion or ligation for ovarian cancer prophylaxis. J Minim Invasive Gynecol 2017; 24: 371-378.

23. Bosteels J, Weyers S, Mathieu C et al. The effectiveness of reproductive surgery in the treatment of female infertility: facts, views and vision. Facts Views Vis Obgyn 2010; 2: 232-252.

24. Perez-Medina T, Bajo-Arenas J, Salazar F et al. Endometrial polyps and their implication in the pregnancy rates of patients undergoing intrauterine insemination: a prospective, randomized study. Hum Reprod 2005; 20: 1632-1635.

25. Pritts EA, Parker WH, Olive DL. Fibroids and infertility: an updated systematic review of the evidence. Fertil Steril 2009; 91: 1215-1223.

26. Fino ENN, Keegan D, Frifo J et al. Surgical correction of uterine septum improves fertility and fertility outcome. Fertil Steril 2005; 84: S470-S471.

27. Valle RF, Ekpo GE. Hysteroscopic metroplasty for the septate uterus: review and meta-analysis. J Minim Invasive Gynecol 2013; 20: 2242. 
28. Missmer SA, Hankinson SE, Spiegelman D et al. Incidence of laparoscopically confirmed endometriosis by demographic, anthropometric, and lifestyle factors. Am J Epidemiol 2004; 160: 784-796.

29. Garrido N, Navarro J, Remohi J et al. Follicular hormonal environment and embryo quality in women with endometriosis. Hum Reprod Update 2000; 6: 67-74.
30. Tapia-Pizarro A, Figueroa P, Brito J et al. Endometrial gene expression reveals compromised progesterone signaling in women refractory to embryo implantation. Reprod Biol Endocrinol 2014; 12: 92.

31. Practice Committee of the American Society for Reproductive Medicine. Endometriosis and infertility: a committee opinion. Fertil Steril 2012;98: 591-598. 